\title{
Shapes with a technical function: an ever-expanding exclusion?
}

\section{Antoon Quaedvlieg 1}

Published online: 15 August 2016

(C) The Author(s) 2016. This article is published with open access at Springerlink.com

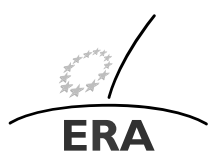

EUROPÄISCHE RECHTSAKADEMIE ACADEMY OF EUROPEAN LAW ACADEMIE DE DROIT EUROPEEN ACCADEMIA DI DIRITTO EUROPEO TRIER - TREVES - TREVIRI

\begin{abstract}
Technical shapes are excluded from trademark protection, in order to prevent trademark monopolies on technical solutions. The Court of Justice applies this anti-monopoly rationale in a broad way, ensuring, as it does, freedom of technical choice for competitors. However, the exclusion also has it limits: it only applies when all essential characteristics of the shape are functional; if this is not the case, the exclusion may not be combined with the other categories of absolute exclusions from trademark protection.

Despite this, the Hauck decision suggests that technical elements may also count, both as elements giving substantial value to the goods or elements resulting from the nature of the goods. This broadens the scope of those exclusions such that it could entail a massive exclusion of shapes of products from trade mark protection.
\end{abstract}

Keywords Trademark protection $\cdot$ Exclusions $\cdot$ Shapes of goods

1 Professor of Private Law, Radboud Universiteit Nijmegen, Faculty of Law, Montessorilaan 10, 6525 HR Nijmegen, Netherlands 


\section{Introduction}

According to Article 4(1)(e)(ii) ${ }^{1}$ of the new Trademark Directive, ${ }^{2}$ shapes of goods that are necessary to obtain a technical result cannot be the subject of a trademark (hereafter referred to as the 'technical exclusion').

The technical exclusion figures as one of the three 'absolute exclusions' of Article $4(1)(e)$. This article is written in a time of transition, following the recast of the European trade mark system: Article 4(1)(e) replaces and amends the old Article 3(1)(e) ${ }^{3}$ and will have to be implemented by the member states by 14 January $2019 .{ }^{4}$ As to the Regulation, the new version has already entered into force on 23 March $2016 .{ }^{5}$ In the old as well as the new version of the Regulation, absolute exclusions figure under Article 7(1)(e). Depending on the context, this article may refer to either Article 3 or 4 of the Directive, or to Article 7 of the Regulation. Although the new texts speak of "the shape, or another characteristic, of goods", it is felt that as far as the technical exclusion is concerned, it will continue to be mainly applied to three dimensional shapes; therefore, this article will speak of "shapes".

The grounds of exclusion mentioned in Articles 4(1)(e) and 7(1)(e) are 'absolute' in the sense that registration of an affected trade mark will be refused, or the trade mark will be declared invalid even if, following the use which has been made of it, it has acquired a distinctive character. According to the TM directive (Article 4, paras. 4 and 5 in the new version), acquired distinctiveness will only be taken into account in a limited number of cases enumerated in those provisions. As the provision makes no mention of acquired distinctiveness in cases under sub-paragraph (e), the Court of Justice reasons, a contrario, that in such cases the exclusion is 'absolute'.

${ }^{1}$ Article 4(1)(e) of Directive 2015/2436. Absolute grounds for refusal or invalidity:

1. The following shall not be registered or, if registered, shall be liable to be declared invalid:

(e) signs which consist exclusively of:

(i) the shape, or another characteristic, which results from the nature of the goods themselves;

(ii) the shape, or another characteristic, of goods which is necessary to obtain a technical result;

(iii) the shape, or another characteristic, which gives substantial value to the goods.

${ }^{2}$ Directive (EU) 2015/2436 of the European Parliament and of the Council of 16 December 2015 to approximate the laws of the Member States relating to trade marks, entry into force: 15 January 2016, OJ L 336/1 of 23 December 2015, pp. 1-26.

${ }^{3}$ The text of Article 3(1)(e) of Trade Mark Directive 2008/95 did not contain the component 'or another characteristic':

Article 3. Grounds for refusal or invalidity

1. The following shall not be registered or, if registered, shall be liable to be declared invalid:

(e) signs which consist exclusively of:

(i) the shape which results from the nature of the goods themselves;

(ii) the shape of goods which is necessary to obtain a technical result;

(iii) the shape which gives substantial value to the goods.

${ }^{4}$ See Article 54.1 of Directive 2015/2436.

${ }^{5}$ Trademark Regulation 2015/2424 of 16 December 2015, OJ L 341/21 of 24 December 2015. 
The essence of the technical exclusion has been elucidated by the Court of Justice in four consecutive judgments. In Philips, ${ }^{6}$ it based all absolute exclusions on an anti-monopoly rationale. Moreover, it gave this rationale a broad interpretation in the sense that it was meant to ensure the freedom of technical choice of competitors (I).

In $\operatorname{Lego}^{7}{ }^{7}$ the Court considerably refined this rationale as not only defining the basis, but also the limits of the exception. It thus helped to create a delicate and functional balance between the interests of trade mark holders and their competitors (II).

In Hauck, ${ }^{8}$ the central importance of the technical exclusion as 'the mother of all exclusions' became manifest. Although the Court of Justice forbade the refusal of trade mark registrations on the basis of a combined application of two or three of the categories of exclusions mentioned under (e), it also ruled that technical elements not only counted for the technical exclusion. They could also qualify as elements which give substantial value to goods, and to some extent, as elements which result from the nature of the goods. At least, that seems to be the most probable interpretation of a still-controversial decision (III).

Finally, in Nestle the refinement was added that the exclusion of the shape of goods which is necessary to obtain a technical result refers only to the manner in which the goods at issue function; it does not apply to the manner in which the goods are manufactured (IV).

These decisions will now be elaborated on in the same order.

\section{Philips: the anti-monopoly rationale}

In Philips, the Court of Justice ruled that a technical exclusion had to be based on an anti-monopoly rationale. Importantly, it also stated that this rationale had to be interpreted as one allowing freedom of choice for competitors.

Preventing trade mark protection from granting a monopoly The Court first stated that the exclusions under sub-paragraph (e) would have to be interpreted, like all other exclusions under para. 1 of Article 3 , in the light of the public interest underlying them. ${ }^{9}$ It went on to say that the rationale of the grounds for refusal in Article 3(1)(e) in general - that is to say, in relation to all three categories of shape marks mentioned under sub-paragraph (e)—was to prevent trade mark protection from granting a monopoly on technical solutions or functional characteristics of a

\footnotetext{
${ }^{6}$ Case C-299/99 Philips vs. Remington [2002] ECR I-05475; Spoor [13]; Grosheide [6]; Gielen [5]; Gevers/Teeuwissen [3]; Quaedvlieg [11]; also see Verkade [16]; cf. further Suthersanen [14]; Fezer [2], p. 468; van Voss [15].

${ }^{7}$ Case C-48/09 Lego Juris/OHIM and Mega Brands [2010] ECR I-08403; Quaedvlieg [10], para. 94; de Wit/Vlaar [1], para. 85 .

${ }^{8}$ Case C-205/13 Hauck vs. Stokke, ECLI:EU:C:2014:2233; Gielen [4]; Haak [7], para. 11; Pinckaers [9], para. 24; Kur [8].

9" 77 . The various grounds for refusal of registration listed in Article 3 of the Directive must be interpreted in the light of the public interest underlying each of them" (see, to that effect, Joined Cases C-108/97 and C-109/97 Windsurfing Chiemsee [1999] ECR I-02779, paras. 25-27).
} 
product $^{10}$ which a user is likely to seek in the products of competitors. The Court added that a trade mark right should not form an obstacle preventing competitors from offering products with the same functional characteristics. ${ }^{11}$

At this general level, the Court might have somewhat overstated the importance of the role of technical subject matter in Article 3(1)(e) as a whole. It is not immediately clear why, for example, the exclusion of shapes which give substantial value to the goods should find its sole justification in preventing monopolies on technical characteristics. However, the judgment did make clear, not only how much importance the Court attaches to the technical exclusion, but also that as early as in 2002, this exclusion at least was also considered fit to play a considerable role under the two other categories of exclusions. This special role of the technical exclusion would be confirmed in later jurisprudence, and especially in Hauck.

Technical solutions which a user is likely to seek in the product On the other hand, the Court formulated in para. 78 of its ruling a condition which may in some cases be of material importance. Article 3(1)(e) prevents trade mark protection from granting its proprietor a monopoly on technical solutions which a user is likely to seek in the products of competitors. Although the Court provided no further explanation regarding this condition, it recalled certain cases in which a trade mark right had been acquired in shapes to which a technical function could be attributed, however without that function being of material importance for the average user. For example, the District Court of The Hague had had to deal with the octagonal shape of cigarette packages. Their particular shape made these packages stronger, but it was a functional characteristic being of no relevance for average consumers, with the possible exception of persons wishing to protect their cigarettes in particularly harsh circumstances, like the fishermen participating in crab catching in the northern ice seas. The condition that the users must be likely to seek the functional characteristics in the shape, allows the upholding of trade mark rights in shapes where those features do have a distinctive function and do not in reality fulfil a technical function. The question remains of where the limit is if a minority of the public does attach an interest to the function of those characteristics.

The freedom of choice for competitors In the next paragraph (para. 79) of the ruling, the Court considered more particularly the elements necessary in order to obtain a technical result, as meant in Article 3(1)(e), second indent. This obviously is the legal exclusion most specifically intended to preclude the registration of shapes whose essential characteristics perform a technical function.

\footnotetext{
${ }^{10} \mathrm{Up}$ to now, the Court has made no precise distinction between the 'technical solutions' and the 'functional characteristics' of a product. In our view, both terms probably relate to the same elements, and trying to make a distinction might cause considerable complications without offering more legal clarity. In this contribution, both terms will be used as interchangeable.

11 "78. The rationale of the grounds for refusal of registration laid down in Article 3(1)(e) of the Directive is to prevent trade mark protection from granting its proprietor a monopoly on technical solutions or functional characteristics of a product which a user is likely to seek in the products of competitors. Article 3(1)(e) is thus intended to prevent the protection conferred by the trade mark right from being extended, beyond signs which serve to distinguish a product or service from those offered by competitors, so as to form an obstacle preventing competitors from freely offering for sale products incorporating such technical solutions or functional characteristics in competition with the proprietor of the trade mark."
} 
The court repeated that the exclusivity inherent in a trade mark right would limit the possibility of competitors supplying a product incorporating such a function. Importantly however, it added that it would "at least limit their freedom of choice in regard to the technical solution they wish to adopt in order to incorporate such a function in their product." 12 The anti-monopoly rationale of Article 3(1)(e) therefore aims at safeguarding the freedom of choice of competitors. That means that the technical subject matter is a matter of free choice, even if, in the case where alternative shapes or alternative methods would be available to reach the same result, a trade mark right in a shape enabling the achievement of a particular technical result would not provide a monopoly in the economic sense. Even if a (great) number of alternative products with different shapes is available on the market for the same function, a technical shape remains a matter of free choice, and a competitor can make, in the technical and functional field, a free choice of the shape he prefers. The provision prevents such signs and indications from being reserved to one undertaking alone. ${ }^{13}$

The court thus created a clear rule which prevents masses of legal complications. For example, it would not always be so easy to establish whether alternative shapes available on the market really offer a solution equivalent to the shape the competitor prefers (and whether for that reason, a monopolistic effect in the narrow sense would be avoided). In many cases alternative shapes will be equivalent in some respects but not in others. Consequently, they may be relevant for some customers, and less relevant for others. All such complications are avoided by the interpretation adopted by the Court.

Other shapes which could achieve the same technical result The question which had been put to the Court of Justice in Philips also enquired whether technical exclusion could be overcome by establishing that there were other shapes which could obtain the same technical result. The Court of Justice simply answered in para. 83 that "Article 3(1)(e), second indent, precludes registration of a sign consisting of that shape, even if that technical result can be achieved by other shapes."14

It is easy to confuse this question with the one that was dealt with above: whether the presence of alternative shapes could overcome the exception. However, against the specific background of the Philips case, the question and answer dealt with in paragraph 83 could also have had a more restricted meaning. The main question at issue may not have been the (broader) question of the existence of alternative shapes

12“79. As regards, in particular, signs consisting exclusively of the shape of the product necessary to obtain a technical result, listed in Article 3(1)(e), second indent, of the Directive, that provision is intended to preclude the registration of shapes whose essential characteristics perform a technical function, with the result that the exclusivity inherent in the trade mark right would limit the possibility of competitors supplying a product incorporating such a function or at least limit their freedom of choice in regard to the technical solution they wish to adopt in order to incorporate such a function in their product."

13 "80. As Article 3(1)(e) of the Directive pursues an aim which is in the public interest, namely that a shape whose essential characteristics perform a technical function and were chosen to fulfil that function may be freely used by all, that provision prevents such signs and indications from being reserved to one undertaking alone because they have been registered as trade marks." (see, to that effect, Windsurfing Chiemsee, para. 25).

${ }^{14}$ Philips, para. 83. 
for shaving devices - of course such shapes existed, in plentiful abundance, in relation to both electrical and non electrical devices-but, rather, the more restricted question of whether all kinds of secondary, minor variations (for which the shape of Philips' triangular, three-headed rotary electric shaver probably also offered scope) could overcome the technical exclusion.

This question is of independent relevance. As followed from the previous considerations of the Court, the technical exclusion was bound to apply in the Philips case. In principle, the essential characteristics of the triangular shape of the shaver performed a technical function. Consequently, competitors were held free to choose any technical shape users would be likely to look for. But was it conceivable, in that case, that the technical exclusion could still be overcome-in other words, would protection of the shape by a trade mark still be allowed-if it could be shown that an exact copy was not indispensable for achieving the technical result? In that case, several or perhaps even many minor variations of such a shape would still have been imaginable. Perhaps, the combination of such minor variations could even result, eventually, in a shape clearly distinguishable from the Philips shaver.

However, such circumstances proved to be of no avail: the Court of Justice found that regardless of the possibility of other forms, the technical exclusion applied. Neither does the wording used by the Court distinguish between the first case (i.e., where very different shapes exist which can achieve the same function) and the second case (i.e., where the same technical shape can still be produced in different variations). The Court ruled, in general terms, that the technical exclusion precluded registration of technical shapes, even if there were other shapes which could achieve the same technical result (paras. 81-83).

Risks of trade mark protection for shapes allowing for minor variations One might wonder what has led the Court to take a relatively hard line and to consider the possibility of minor variations to be of no relevance, even if it seems that perhaps such minor differences could easily be realised.

One reason is easy to imagine, and the Court later mentioned it in Lego: ${ }^{15}$ it is not excluded that such variations, despite their difference in form, might still fall under the scope of the trade mark right, so that in the end, the trade mark right would still give its proprietor an exclusive right with a (semi-)monopolistic effect.

A second circumstance however should also be observed. A more nuanced approach would oblige competitors to be extremely prudent. Before copying a technical shape, they would have to study very carefully whether and to what extent a feature could possibly be given other shapes, test whether (and in what combination) such variations would actually work, and still run the risk that their choices would eventually be challenged in court proceedings with a considerable uncertainty as to the outcome. Such uncertainty could deprive the rule of technical freedom from much of its effect. Many entrepreneurs might prefer to refrain from taking advantage of that freedom in order to avoid risks of being accused of trade mark infringement, to be involved in court proceedings, or to be regarded by their customers as sellers of potentially infringing goods. An effective regime of freedom of technical imitation requires a certain margin of certainty, without which it will not work.

${ }^{15}$ Case C-48/09 P Lego [2010] ECR I-08403, para. 56, also see para. 57. 
A misleading formula: the functional characteristics are attributable to the technical result Finally, para. 83 in Philips contained a formula which could lead to mistakes. It said that

"where the essential functional characteristics of the shape of a product are attributable solely to the technical result, Article 3(1)(e), second indent, precludes registration."

However, as would later be established in $\operatorname{Lego}^{16}$ it is necessary that all essential functional characteristics of the shape of a product are attributable solely to the technical result. Therefore, where para. 83 speaks of "the essential functional characteristics" the word 'functional' should be omitted. Where (all) the essential characteristics of the shape of a product are attributable solely to the technical result, Article 3(1)(e), second indent, should preclude registration.

In its present wording, para. 83 could lead to unacceptable results. Countless objects of industrial design contain one or several essential functional characteristics that are attributable solely to the technical result; but as long as not all essential characteristics of the shape are functional, and the shape therefore also contains other essential characteristics which clearly do not fulfil a technical function, trade mark protection (of course) is possible. For example, the highly distinctive shape of a car should be eligible for trade mark protection even if the essential functional characteristics of the shape - its wheels - are attributable solely to the technical result. It is telling that the formula of para. 83 in Philips has not been repeated in later decisions.

Trade marks may not be used to perpetuate exclusive rights In para. 82 of Philips, the Court of Justice stated that the technical exclusion reflects the aim of not allowing individuals to use registration of a mark in order to acquire or perpetuate exclusive rights relating to technical solutions. Gradually, this element of nonperpetuation, only rudimentarily mentioned in Philips, would find an ever stronger expression in the jurisprudence.

In the Lego judgment, the Court of Justice stressed again that trade mark rights may not be used to perpetuate, indefinitely, exclusive rights relating to technical solutions (para. 45); in the system of intellectual property rights developed in the European Union, technical solutions are capable of protection only for a limited period (para. 46). These considerations therefore show a strong emphasis on the argument of non-perpetuation. Of course, they must be read in context with the case: the obvious intention of Lego was to perpetuate the exclusive rights in the famous Lego-bricks by bringing them under trade mark protection. However, the anti-monopoly rationale was certainly not abandoned in Lego. Paragraph 43 of the judgment clearly expresses the view that the interest underlying Article 7(1)(e)(ii) of the Regulation is to prevent trade mark law granting an undertaking a monopoly on technical solutions of functional characteristics of a product.

\footnotetext{
${ }^{16}$ Lego, para. 52: "[...] that the ground for refusal under Article 7(1)(e)(ii) of Regulation No 40/94 is applicable only where all the essential characteristics of the sign are functional $[\ldots] "$.
} 
So do the judgments in Hauck ${ }^{17}$ and in Nestlé. ${ }^{18}$ But paras. 19 of the Hauck decision/45 of Nestlé place all emphasis in the anti-perpetuation element, almost creating the impression that this is what the anti-monopoly rationale really is about.

That would be a position which cannot be sustained. It is not the perpetuation of the protection of the Lego brick or the Tripp Trapp chair, but the acquisition in general of a trade mark right entailing a technical monopoly, which is the reason why trade mark protection must be excluded.

Even during the time patent protection is possible or is actually granted, trade mark protection must be excluded; not for nothing, Article 3(1)(e) works $a b$ initio and forever. Trade mark protection for technical shapes would risk to ban other shapes from the market, even if these shapes would fall outside the scope of the patent protection, for the mere fact of causing a danger of confusion with the shape of the trade mark holder. In case it would concern a well known shape mark, a competing technical shape could be forbidden for causing dilution. And indeed, once the maximum term of patent protection would be expired, the trade mark holder could try to perpetuate his rights by using the trade mark; but that is only one aspect why trade mark protection is not desirable, and it does certainly not mean that there would not be as much ground to prevent that protection before the expiration of the patent protection.

Emphasis on the non-perpetuation argument is fairly innocuous in relation to patent law and technical characteristics. In relation to technical characteristics, perpetuated protection would in all cases be excluded. However, the same is not true in relation to copyright law, where too much emphasis on the non-perpetuation argument may give rise to misunderstandings. Whereas the functional characteristics excluded by the technical exclusion should never be protected by trade mark law anyhow, the arbitrary elements which can be at the basis of the substantial value exclusion can - on condition that they are capable of distinguishing goods as to their commercial origin - as well be at the basis of the trade mark protection itself.

Later jurisprudence, and especially the Hauck judgment (dealt with in the text below) was susceptible of giving rise to the impression that the fact alone that copyright has lapsed makes 'perpetuation' of the protection by trade mark law undesirable; but what applies in the case of patent law, does not apply here. It would be absurd to suppose that trade mark protection in a certain logo would have to lapse, just because the copyright term had expired. Therefore, the anti-monopoly rationale is primary, and the aim of preventing perpetuation of the exclusive right is subordinate to it. Where the acquisition of an intellectual property right would not give rise to a danger of monopolistic effects, it should be no problem that it survives or perpetuates other rights which lapse. Importantly, trade mark law contains other and less drastic tools to take into account the fact that copyright has expired. For example, the fact of the expiration could be an argument for the user to invoke a valid reason for his use in case he is confronted with an action by the trade mark holder based on the protection of the goodwill in a well-known mark. ${ }^{19}$

\footnotetext{
${ }^{17}$ Hauck, para. 18 .

${ }^{18}$ Nestlé, para. 44.

${ }^{19}$ Cf. Article 10(2)(c) and 10(6) Directive 2015/2436; Article 9(2)(c) of Regulation 2015/2424; also see the reference to use for an artistic expression in recital 21 of the Regulation.
} 
Conclusion Philips provided a robust technical exclusion. Rather than (only) preventing monopolies as to a certain technical result (by applying the technical exclusion solely where no alternative shape leading to that result is available), it ensured the freedom for all to use all means (shapes) necessary to obtain these results: where alternative shapes exist, all those alternatives are free; competitors enjoy freedom of choice as to the shape they prefer.

Moreover, in order to fall under the technical exclusion, it is not required that a shape is totally determined by its technical function. Even if all kinds of minor variations of the shape can still be imagined, competitors are not obliged to bother about such details and alter the technical shape within the possibilities thus left open. The principle is freedom of technical subject matter, and the Court creates the conditions ensuring that this freedom can, without prohibitive complications, be exercised in practise.

\section{Lego: "all essential characteristics"}

In Lego,${ }^{20}$ the Court used the same rationale which provides the basis for the technical exclusion to also define its boundaries, thus providing guarantees for a healthy and fair system of competition. ${ }^{21}$ But it showed above all that in order to achieve this goal, (i) only the essential characteristics of the shape mattered; and (ii) these essential characteristics would all have to fall under the applicable exclusion.

Balancing of two considerations The most important element added by the Lego decision was that the Court considered that the rules laid down by the legislature should reflect the balancing of two considerations, both of which are likely to help establish a healthy and fair system of competition (para. 44). On the one hand, undertakings may not use trade mark law in order to perpetuate, indefinitely, exclusive rights relating to technical solutions (para. 45), and the legislature has laid down with particular strictness that shapes necessary to obtain a technical result are unsuitable for registration as trade marks, even if they have become distinctive (para. 47). On the other hand however, the legislature took into account that any shape of goods is, to a certain extent, functional. By using the terms 'exclusively' and 'necessary', it ensured that solely shapes of goods which only incorporate a technical solution, and whose registration as a trade mark would therefore actually impede the use of that technical solution by other undertakings, were not to be registered.

Paragraph $51 \mathrm{ff}$. of the Lego decision show the consequences of that system for the balance between the trade mark holders and their competitors:

The condition that the sign consists 'exclusively' of a technical shape On the one hand, the condition that the sign consists 'exclusively' of the shape of goods which is necessary to obtain a technical result is only fulfilled when all the essential characteristics of a shape perform a technical function (para. 51). That is in the interest of the trade mark holders.

\footnotetext{
${ }^{20}$ Case C-48/09 P Lego [2010] ECR I-08403.

${ }^{21}$ Lego, para. 44.
} 
However, most of the other conclusions of the Court serve the interests of users. The Court of Justice holds that the presence of one or more minor arbitrary elements in a three-dimensional sign, all of whose essential characteristics are dictated by the technical solution, does not alter the conclusion that the sign consists exclusively of the shape of goods which is necessary to obtain a technical result. However, the sign cannot be refused registration as a trade mark if the shape of the goods at issue incorporates a major non-functional element, such as a decorative or imaginative element which plays an important role in the shape.

Non-functional elements must be 'essential characteristics' The requirement that the non-functional element must play an important role follows from the fact that the shape will only escape the application of the technical exclusion when at least one of the 'essential' characteristics is of a non-functional nature. ${ }^{22}$ The expression 'essential characteristics' refers to the most important elements of the sign. ${ }^{23}$ Consequently, only if one of the 'most important' elements of a shape has a non-functional nature will that shape be eligible for registration as a trade mark.

The condition that the shape is 'necessary' to obtain a technical result The conclusions of the Court with regard to the condition that the shape must be 'necessary' to obtain a technical result are intriguing. Their general purport is crystal clear: the existence of other shapes which could achieve the same technical result does not in itself preclude application of the technical exclusion (para. 57). But if one endeavours a more detailed interpretation, some questions rise.

In para. 55, the Court pointed out that the fact that alternative shapes ${ }^{24}$ exist does not in itself mean that registering a shape as a trade mark would have no effect on the availability of a technical solution. The trade mark protection of a purely functional product shape would prevent other undertakings not only from using the same shape, but also from using similar shapes. A significant number of alternative shapes might therefore become unusable (para. 56). That would be particularly so, the Court of Justice added, if various purely functional shapes of goods were registered at the same time. That might completely prevent other undertakings from manufacturing and marketing certain goods having a particular technical function (para. 57).

'Similar' alternative shapes The 'similar' alternative shapes obviously concern shapes showing minor variations. As such shapes fall under the scope of protection of the exclusive right, it is obvious that the rationale of the technical exclusion demands that the exclusion must extend, not only to technical shapes which are totally determined by their technical function, but also to those which involve minor variations, as most or all of these would risk to be equally swallowed by the monopoly. Lego had contended that the characteristic bosses of the Lego-bricks could still be

\footnotetext{
${ }^{22}$ Cf. Lego, paras. 51, 72.

${ }^{23}$ Cf. Lego, para. 69.

${ }^{24}$ Para. 54 refers to alternative shapes "with other dimensions or another design, capable of achieving the same technical result". 'Other dimensions' appears to refer to alternative forms in general representing variations of rather minor importance; by contrast, 'another design' could indicate major differences. However, it looks as if para. 54 contains a very general description in the first place.
} 
varied in endless ways: in form (round, oval, star form), in height, in diameter, in versions either closed or open above, and in countless other ways. This kind of variations was apparently considered by the Court to be 'minor'.

'Various purely functional shapes' The question which must be answered now, is what the Court might have meant, in paragraph 57, with the words 'various purely functional shapes'. In that case, it is indicated, other undertakings might be completely prevented from manufacturing and marketing certain goods having a particular technical function.

One could think of the possibility that a trade mark holder would register several 'similar' alternative shapes, thereby trying, insofar as possible, to bring all imaginable variations under the scope of his registrations. But in that case one could not speak of 'purely' functional shapes, as the fact itself that variations of the same shape are registered shows that the shape is not purely functional. Moreover, the fact that an undertaking tries to totally monopolise one shape capable of achieving a technical result in all its variations, would still not have as a result other undertakings being "completely prevented from manufacturing and marketing certain goods having a particular technical function", as the Court indicates. Most likely therefore, the Court of Justice was actually speaking about different technical solutions, finding their expression in totally different shapes. ${ }^{25}$ It is obvious that the registration, as a trade mark, of several such shapes would result in a broad monopolistic position.

Reference to conclusions 81 and 83 in Philips The Court of Justice concluded by stating that its preceding conclusions "are moreover reflected in paragraphs 81 and 83 of Philips, which state that the existence of other shapes which could achieve the same technical result does not in itself preclude application" of the technical exclusion.

The Lego bricks In paragraphs 59 and 60, the Court turned to the Lego bricks in question. The fact that Lego's competitors did not need to place on the market toy bricks whose shape and dimensions were in all respects identical to those of the Lego brick, could not prevent application of the technical exclusion (59). It obviously concerned 'minor variations'. The conclusion of paragraph 59 applied a fortiori now that it had been found that the Lego bricks incorporate the technically preferable solution, as it would be difficult for the competitors of the proprietor of that mark to place on the market shapes of goods constituting a real alternative (para. 60).

Conclusion In Lego, the Court of Justice clarified that in order for the technical exclusion to be applicable, all essential characteristics of the shape had to be functional. After Philips, uncertainty could have persisted as to that element. Apart from that, the contours appeared of a distinction between similar technical alternatives and more radical technical alternatives based on other purely functional shapes. For the application of the technical exclusion however, that distinction made no difference: in both cases, trade mark protection was 'absolutely' excluded.

${ }^{25}$ For examples see Quaedvlieg [12]. 


\section{Hauck 2014: the technical exclusion king}

The Hauck judgment of 2014 illustrated how central the position of the technical exclusion is in the system of the absolute exclusions. Its effect is not confined to the technical exclusion in the narrow sense, mentioned in the second indent of Article 4(1)(e); the exclusion of functional shapes also plays an important role in the other two categories mentioned in the first and third indent under (e), the shapes which result from the nature of the goods themselves and the shapes which give a substantial value to the good. But the full importance of these findings can only be understood in the light of a rule formulated by the Court of Justice at the end of its decision, where it forbids the combined application of the absolute grounds of refusal. We will start there.

The prohibition of combined application of the absolute grounds of refusal The Court of Justice decided that the absolute grounds of refusal may not be applied in combination. It considered that it follows from the wording of Article 3(1)(e)—-"signs which consist exclusively of the shape [etc.]"- that the three grounds for refusal operated independently. ${ }^{26}$ If any one of the criteria listed in Article 3(1)(e) of the trade marks directive was satisfied, a sign consisting exclusively of the shape of the product or of a graphic representation of that shape could not be registered; ${ }^{27}$ in contrast, the public interest objective underlying the application of the three grounds for refusal precluded refusal of registration where none of those three grounds was fully applicable. ${ }^{28}$

Nevertheless, the Court apparently considered it conceivable that a sign could be denied registration on the basis of a number of grounds for refusal. It holds this to be irrelevant so long as any one of those grounds fully applied to that sign. ${ }^{29}$ It therefore could not in principle be excluded that a shape as a whole was excluded on the basis of the nature of the goods and/or the technical exclusion and/or the substantial value exclusion — and that consequently, all or a least some of its essential elements — could simultaneously be considered 'beautiful' and/or 'useful' and/or as resulting from the nature of the good.

In the light of the principle that the three grounds of exclusion could not be applied in combination, it was striking that-for the moment-it did not seem excluded that technical and functional elements might be counted as giving substantial value to goods or as resulting from their nature, as will be demonstrated now.

The Tripp Trapp high chair as a mixture of beauty and function The object of the proceedings in the Hauck case was the famous Tripp Trapp high chair. The Dutch Hoge Raad had established that although the shape of the 'Tripp Trapp' chair gave it significant aesthetic value, at the same time it had other characteristics (safety,

\footnotetext{
${ }^{26}$ Hauck, para. 39.

${ }^{27}$ Hauck, para. 40.

${ }^{28}$ Hauck, para. 42.

${ }^{29}$ Hauck, para. 41 .
} 
comfort and reliability) which gave it an essential functional value. ${ }^{30}$ The question to deal with was whether the exclusion of shapes which gave a substantial value to a product could be applied to a sign which consisted exclusively of the shape of a product with several characteristics each of which could give that product substantial value. $^{31}$

Apparent contradictions in the wording of the decision The Court of Justice, explicitly invoking the anti-monopoly ratio, decided that for the purpose of the substantial value exclusion, functional characteristics as well as a significant aesthetic elements could give substantial value to the goods: ${ }^{32}$

32 Indeed, the concept of a 'shape which gives substantial value to the goods' cannot be limited purely to the shape of products having only artistic or ornamental value, as there is otherwise a risk that products which have essential functional characteristics as well as a significant aesthetic element will not be covered. In that case, the right conferred by the trade mark on its proprietor would grant that proprietor a monopoly on the essential characteristics of such products, which would not allow the objective of that ground for refusal to be fully realised.

However, the decision was not without ambiguity. In para. 31, the Court of Justice considered that the application of the substantial value exclusion could not be ruled out when, in addition to its aesthetic function, the product concerned also performed other essential functions. In contrast, in para. 32 the Court spoke of products having functional characteristics apart from their aesthetic elements. However, it can make quite a difference whether one talks of functions or characteristics.

The rule formulated in para. 31-namely, that the substantial value exclusion may apply when, in addition to its aesthetic function, a product also performs other functions-is not very surprising. It must be supposed that it leaves intact the rule that one of the exclusions fully applies. As the product has, in the first place, an aesthetic function, that 'fully applying ground' supposedly would be the substantial value exclusion. Obviously, once that condition has been fulfilled, it cannot in the least be a problem that in addition to its aesthetic function, the product also performs other functions; one could think of a beautiful loudspeaker that apart from its aesthetic function has an obvious useful function. This 'functional' approach therefore is a disciplined, transparent, orthodox application of the Court's own doctrine. One can fully understand that many specialists prefer to read the judgment in this way. ${ }^{33}$ However, if this is the right interpretation, why then does not the Court simply repeat its finding in para. 41, that the sign cannot be registered if any one of the criteria listed in Article 3(1)(e) of the trade marks directive is satisfied?

In contrast, in paragraph 32 of its ruling, quoted above, the Court of Justice does not regard the functions of the product but its characteristics. Even if some of the characteristics of the aesthetic shape have a functional nature, the substantial value

\footnotetext{
${ }^{30}$ Hauck, para. 29.

${ }^{31}$ Hauck, para. 28.

${ }^{32}$ Hauck, paras. $30-32$.

${ }^{33}$ See, amongst others, Gielen [4], under (7).
} 
exception applies. That means that functional characteristics as such could give a substantial value to the goods. If this interpretation is applied, it will have a result comparable to the combined application of the technical exclusion and the substantial value exclusion; with the difference that as the functional characteristics are considered to give substantial value, that last exclusion 'fully applies' and no combined application is needed.

Although bold, this broad interpretation of the decision deserves serious consideration. It connects to the legal question the Court had to answer: whether the exclusion of shapes which give a substantial value to the good may be applied to a sign which consists exclusively of the shape of a product with several characteristics each of which may give that product substantial value. That same formula is repeated in the operative part of the decision: "The third indent of Article 3(1)(e) of Directive 89/104 must be interpreted as meaning that the ground for refusal of registration set out in that provision may apply to a sign which consists exclusively of the shape of a product with several characteristics each of which may give that product substantial value." That is clearly different from the 'functions' approach.

Secondly, the Court of Justice referred to Advocate General Szpunar's Conclusion. ${ }^{34}$ The Advocate General recognises the independence of the grounds for absolute exclusion, but unmistakably alludes to a combination of grounds of exclusion within the substantial value exclusion. As he explains, the interpretation of the substantial value exclusion he favours does not exclude that, apart from aesthetic functions, the good also fulfils other functions. ${ }^{35}$ The Advocate General then adds: "On that interpretation of Article 3(1)(e), joint application of the grounds at issue does not appear to me to be necessary to attain the objective sought by that provision" (italics added). ${ }^{36}$ In other words: by opting for an interpretation which allows to internally combine the grounds of exclusion, the possibility of an external combination of the grounds of exclusion is not needed anymore in order to meet the goal of the exclusion. That also makes clear that, despite his reference to the 'functions' of the product, the Advocate General is in reality speaking about its characteristics.

In its key consideration in para. 32, the Court of Justice recognised that in the light of the anti-monopoly rationale of the grounds of refusal, this 'internal combination' of grounds was necessary. Obviously, this reference to the rationale would not have been necessary if all the essential characteristics would have contributed to the aesthetic value of the product. In that case, the substantial value exception clearly would have 'fully' applied. Only in the case of a combination of essential elements of which some were of an aesthetic and others of a functional nature, was the reference to the anti-monopoly rationale needed in order to justify the decision.

The exclusion of shapes which result from the nature of the goods themselves For a long time, the shape which results from the nature of the goods themselves has remained the dark planet of the absolute exclusions, and perhaps it still does. However, it is not the intention here to clarify what exactly must be understood by a

\footnotetext{
${ }^{34}$ In particular to paras. $99 \mathrm{ff}$. of the Conclusion of Advocate General Szpunar, ECLI:EU:C:2014:322.

${ }^{35}$ Conclusion of Advocate General Szpunar, para. 102.

${ }^{36}$ Conclusion of Advocate General Szpunar, para. 103.
} 
shape which results from the nature of the goods themselves. This contribution will concentrate exclusively on the role of technical and functional elements within the 'nature-exclusion'.

In paras. 24-26 of its Hauck ruling, the Court held that the exclusion of shapes which result from the nature of the goods themselves (and further, the exclusion of the nature of the goods) cannot be interpreted as applying only to signs which consist exclusively of shapes which are indispensable to the function of the goods in question, leaving the producer of those goods no leeway to make a personal essential contribution. That would not allow the objective of the ground for refusal set out therein to be fully realised, because the ground for refusal should not only apply to 'natural' products which have no substitute, and 'regulated' products the shape of which is prescribed by legal standards, but also to shapes with essential characteristics which are inherent to the generic function or functions of such goods. These signs must, in principle, also be denied registration.

Hauck puts so much emphasis on the criterion of the generic function that the statutory criterion of the nature of the goods seems almost condemned henceforth to live in the shadows. The Court holds that "signs consisting of the shapes formed by such products could not be registered in any event because of their lack of distinctive character". ${ }^{37}$ But above all, the exclusion not only extends to all shapes which are indispensable to the function of the goods in question-which includes, again, technical and functional shapes-but also to shapes with essential characteristics which are inherent to the generic function or functions of such goods. The criterion of the generic function leaves many questions. To some extent, the shape of (almost) every product of industrial design shows a reference to the generic function of the product. If applied in a broad manner, the criterion of the generic function could almost categorically exclude industrial design from shape mark protection. Consequently, the most absolute regime - the North Korea of the technical exclusion - is not found under the realm of the technical exclusion itself, but in that of its neighbour, the exclusion of the nature of the goods.

The technical exclusion within the exclusion of the nature of the goods Whatever view one takes of the criterion of the generic function, it is impossible to ignore that both the shapes indispensable for the function of the goods, as shapes with essential characteristics which are inherent to the generic function or functions of such goods, must be denied registration under the exclusion of the nature of the goods. The fact that the technical exclusion is thus allowed to be deployed in full under this category too makes it even more plausible that the same applies to the exclusion of shapes which give substantial value to the goods. Whereas an external combination of the technical exclusion with other grounds is forbidden, an internal combination is allowed.

${ }^{37}$ Hauck, para. 24 , in fine. In its absoluteness, this seems a rather sweeping statement. 


\section{Nestlé v Cadbury (“Kitkat four-finger shape”)}

In Nestlé $v$ Cadbury, ${ }^{38}$ a case about the shape mark registration for the famous KitKat four-finger shape, the referring court had asked whether Article 3(1)(e) of Directive 2008/95 had to be interpreted as precluding registration as a trade mark of a sign consisting of the shape of goods where that shape contains three essential features, one of which results from the nature of the goods themselves and two of which are necessary to obtain a technical result.

Fully in accordance with its earlier decision in Hauck, the Court ruled that it is possible that the essential features of a sign may be covered by one or more grounds of refusal set out under Article 3(1)(e). However, in such a case, registration may be refused only where at least one of those grounds is fully applicable to the sign at issue. $^{39}$

What was new was the decision that the technical exclusion refers only to the manner in which the goods at issue function. ${ }^{40}$ It does not apply to the manner in which the goods are manufactured. Therefore, characteristics of the shape of the four-finger crisp which had been caused by the production process did not fall under this exclusion. Article 3(1)(e)(ii) of Directive 2008/95, the Court argued, aims at preventing a monopoly on technical solutions which a user is likely to seek in the goods of competitors. From the consumer's perspective, the manner in which the goods function is decisive and their method of manufacture is not important.

\section{Conclusion}

The four decisions rendered by the Court of Justice, as from 2002, on the subject of the technical exclusion have brought much clarity in a field which is not the easiest one in trade mark law. What are the main lessons?

It must be welcomed that in Philips, the Court immediately based the technical exclusion as well as the two other categories of absolute exclusions of shape marks on an anti-monopoly rationale. However, not only technical shape marks which cause a monopoly are excluded from registration as a trade mark. The exclusion extends to all exclusively technical shapes. Whereas a genuine anti-monopoly rationale could also lead to a more narrow interpretation of the exclusion, this broad interpretation fits well into the system of intellectual property. The protection of technical subject matter is generally reserved to patent law. In cases where functionally determined shape does not create a monopoly as to achieving a technical result, but still prevents the application of one (of several) means to achieve that result, the registration as a trade mark would allow trade mark law a role as a competitor of patent law, free of the costs and conditions of a patent right. That clearly would not be desirable.

The Lego decision showed how deeply the anti-monopoly rationale influences the absolute exclusions of shape marks. In the light of that ratio, it is clear that only the

\footnotetext{
${ }^{38}$ Case C-215/14 Nestlé v Cadbury, ECLI:EU:C:2015:604.

${ }^{39}$ Nestlé v Cadbury, para. 48.

${ }^{40}$ Nestlé v Cadbury, paras. 52-57.
} 
essential characteristics of the shape matter; the rest is irrelevant. It also is obvious that as to these essential characteristics, it must be required that they all must fall under the absolute exclusion which is applied. As far as the technical exclusion is concerned, that means that if one of the essential elements is of an arbitrary nature, the exclusion finds no application.

Whereas Lego showed that one (essential) aesthetic element in a technical shape can block the application of the technical exclusion, Hauck and Nestlé made clear that by contrast, one or more (essential) technical or functional elements in an aesthetic shape, or in a shape which results from the nature of the goods, is not a problem: technical and functional characteristics can give substantial value or belong to the nature of the good.

In Lego, it was clear that the Court of Justice had very carefully considered both sides of the coin. It considered the interest of users and competitors that trade mark registration should not be used to create (semi-)monopolies in goods, as well as the interest of the trade mark holder that the absolute exclusions should not be interpreted too broadly: they must only be applied where an actual danger of a monopolising effect exists. In Hauck, that last preoccupation is far less visible. The potential scope of application of the absolute exclusions is defined in a very broad manner without an indication of where the boundaries are. Still, in the light of Lego we have the certainty that those boundaries exist. This will thus be the next point for the Court to clarify.

Open Access This article is distributed under the terms of the Creative Commons Attribution 4.0 International License (http://creativecommons.org/licenses/by/4.0/), which permits unrestricted use, distribution, and reproduction in any medium, provided you give appropriate credit to the original author(s) and the source, provide a link to the Creative Commons license, and indicate if changes were made.

\section{References}

1. de Wit, S., Vlaar, S.: Note on Case C-48/09 Lego Juris/OHIM and Mega Brands. IER, 573-586 (2010)

2. Fezer, K.-H.: Entwicklungslinien und Prinzipien des Markenrechts in Europa. GRUR, 457 (2003)

3. Gevers, E., Teeuwissen, D.: Note on Case C-299/99 Philips vs. Remington. BMM Bulletin, 188-199 (2002)

4. Gielen, C.: Note on Case C-205/13 Hauck vs. Stokke. NJ, 349 (2015)

5. Gielen, C.: Note on Case C-299/99 Philips vs. Remington. Ars Aequi, 43-49 (2003)

6. Grosheide: Note on Case C-299/99 Philips vs. Remington. IER, 251-262 (2002)

7. Haak, M.F.J.: Note on Case C-205/13 Hauck vs. Stokke. BIE, 61-70 (2015)

8. Kur, A.: Note on Case C-205/13 Hauck vs. Stokke, GRUR, 1097 (2014)

9. Pinckaers, J.C.S.: Note on Case C-205/13 Hauck vs. Stokke. IER, 176-185 (2015)

10. Quaedvlieg, A.: Note on Case C-48/09 Lego Juris/OHIM and Mega Brands. BIE, $408-423$ (2010)

11. Quaedvlieg, A.: Note on Philips vs. Remington. BIE (89), 547-555 (2003)

12. Quaedvlieg, A.: Overlap/relationships between copyright and other intellectual property rights. In: Derclaye, E. (ed.) Research Handbook on the Future of EU Copyright, pp. 480-516. Edward Elgar, Cheltenham Glos (2009)

13. Spoor, J.H.: Note on Philips vs. Remington. NJ, 481 (2003)

14. Suthersanen, U.: The European Court of Justice in Philips vs. Remington-Trade Marks and Market Freedom. IPQ, 257 (2003)

15. Heerema van Voss, M.: Vormmerken en techniek, vóór en ná Philips/Remington. BMM Bulletin, 182-187 (2002)

16. Verkade, D.W.F.: actualiteiten. BIE, 447 (2002) 